\title{
Clinical profile of neonates admitted to a neonatal intensive care unit at a referral hospital in South India
}

\author{
Anurekha V', Kumaravel KS ${ }^{2}$, Kumar $\mathbf{P}^{3}$, Satheesh kumar $D^{4}$ \\ ${ }^{1}$ Dr. Anurekha V, Assistant Professor, Govt. Mohan Kumaramangalam Medical College, Salem, Tamilnadu, \\ ${ }^{2}$ Dr. Kumaravel K.S., Professor, Govt. Dharmapuri Medical College, Dharmapuri, Tamilnadu, ${ }^{3}$ Dr. Kumar P., Govt. \\ Mohan Kumaramangalam Medical College, Salem, Tamilnadu, ${ }^{4}$ Dr. Satheesh kumar D, Govt. Mohan Kumaramangalam \\ Medical College, Salem, Tamil Nadu, India.
}

Corresponding Author: Dr. Kumaravel K.S, Email: kumaravelks10@gmail.com

\begin{abstract}
Introduction: A country's health is measured in terms of infant mortality. The neonatal care was revolutionized after the inception of NHM. The reduction in mortality can be achieved by systematic approach to common diseases prevailing in the area and by applying the uniform treatment protocol to bring down the mortality. So, this study aims at identifying the morbidity and mortality pattern in a tertiary care referral center. Methodology: Hospital data based retrospective study from Jan' 2016 to Dec' 2017. Results: Total of 7108 neonates was analyzed. Male: female ratio was 1.25:1. Low birth weight babies accounted $48.91 \%$ and pre-term babies around $54.63 \%$. Of this predominant were late preterm babies. Jaundice requiring photo therapy (21.97\%) topped the list of morbidities followed by sepsis (19.27\%) and respiratory distress $(7.86 \%)$. Sepsis (24.93\%), RDS (19.95\%) and birth asphyxia (18.95\%) were the leading causes of mortality. Overall mortality in this study was $11.28 \%$. Conclusion: Hyper bilirubinemia, Sepsis and respiratory distress syndrome were the leading causes of morbidity. Neonatal sepsis can be prevented by enforcing strict hand hygiene and aseptic protocols. Low birth weight and prematurity were the significant contributors to morbidity and mortality. Hence antenatal programs to prevent prematurity and low birth weight babies should be strengthened.
\end{abstract}

Key words: Neonate, Morbidity, Neonatal mortality, Neonatal Intensive Care Unit

\section{Introduction}

Neonatal period is the first 28 days of life since birth. It is considered as the most susceptible period for mortality and morbidity [1]. A country's health status is measured in terms of infant mortality [2]. Neonatal mortality accounts for $2 / 3$ rd of the infant mortality [2]. Current Neonatal Mortality Rate (NMR) in India is $34 / 1000$ live births [3].Tamilnadu stands second lowest with $17 / 1000$ [3]. India contributes to nearly $25 \%$ of global neonatal deaths [4]. Even though there is a drastic decline in NMR,Average Annual Rate of Reduction (AARR) is only less with $3.5 \%$. UN Millennium Development Goals 2015 had seen a reduction of $47 \%$ of under 5 mortality (U5MR).

Sustainable Development Goal 2030 focuses mainly on reduction in neonatal mortality to achieve U5MR [5]. Seventy five percent of neonatal deaths occur in first week of life [6]. Three major causes (78\%) which

Manuscript received: $6^{\text {th }}$ February 2018

Reviewed: $16^{\text {th }}$ February 2018

Author Corrected: $24^{\text {th }}$ February 2018

Accepted for Publication: $28^{\text {th }}$ February 2018 contribute to neonatal mortality in developing countries are prematurity $\&$ low birth weight, neonatal infections and birth asphyxia [7]. In India, the neonatal care saw a revolution under the auspices of National Health Mission (NHM) [8]. After reduction in NMR, the goal is to reduce the morbidity of neonates by disease specific intervention. So, identifying the pattern of medical illness in an area will help the health care providers to plan service priorities [9].

Population specific, systematic comprehensive strategies are needed to reduce the morbidity and mortality at national level [10]. So, this study aims at the identification of factors contributing to neonatal mortality and morbidity in our hospital.

\section{Methodology}

Study Design and Period: It is a hospital data based retrospective study from January 2016 to December 2017 for a period of 2 years. Study Place: It was done 
in Neonatal Intensive Care Unit (NICU) of Government Mohan Kumaramangalam Medical College Hospital, Salem in Tamilnadu state. Inclusion Criteria: All babies admitted in our NICU under 28 days of life. Exclusion Criteria: Neonates Left against Medical
Advice and referred to higher center without definitive diagnosis were excluded. Statistical Analysis- was done using Microsoft Office Excel ${ }^{\odot}$. The standard case definitions of National Neonatology Forum were used. The results were analyzed for frequency.

\section{Results}

A total of 7108 neonates formed the study group after exclusion of neonates left against medical advice and neonates referred to higher centers. Out of them 4366 (61.42\%) were intramural and 2742 (38.57\%) were extramural admissions. Among these 55.52\% were male and $44.47 \%$ were female and the Male: Female sex ratio was $1.25: 1$. More than 50\% babies weighed above $2.5 \mathrm{~kg}$ and low birth weight babies constituted $48.91 \%$. Among this more than one third (38.33\%) are late pre terms and more than $50 \%$ are preterm neonates. Average duration of hospital stay was 6.67 days and more than one third of the babies stayed for more than 7 days.

Table:1: Profile of babies admitted.

\begin{tabular}{|c|c|c|c|}
\hline Characteristics & Intramural & Extramural & Total \\
\hline Number of babies in the study group & $4366(61.42 \%)$ & $2742(38.58 \%)$ & 7108 \\
\hline \multicolumn{4}{|c|}{ Sex distribution } \\
\hline Male & $2363(54 \%)$ & $1584(57 \%)$ & $3947(55.53 \%)$ \\
\hline Female & $2003(46 \%)$ & $1158(43 \%)$ & $3161(44.47 \%)$ \\
\hline \multicolumn{4}{|c|}{ Birth weight distribution } \\
\hline$>2.5 \mathrm{~kg}$ & $2211(50.6 \%)$ & $1420(51 \%)$ & $3631(51.08 \%)$ \\
\hline $1.5-2.499 \mathrm{~kg}$ & $1783(40.8 \%)$ & $1030(37.56 \%)$ & $2813(39.57 \%)$ \\
\hline $1-1.499$ & $283(6.48 \%)$ & $221(8.05 \%)$ & $504(7.09 \%)$ \\
\hline$<1 \mathrm{~kg}$ & $89(2.03 \%)$ & $71(2.58 \%)$ & $160(2.25 \%)$ \\
\hline \multicolumn{4}{|c|}{ Gestational age } \\
\hline$>37$ weeks & $1910(43.74 \%)$ & $1315(47.95 \%)$ & $3225(45.37 \%)$ \\
\hline 34-37 weeks & $1711(39.18 \%)$ & $1014(36.98 \%)$ & $2725(38.33 \%)$ \\
\hline$<34$ weeks & $745(17.06 \%)$ & $413(15.06 \%)$ & $1158(16.29 \%)$ \\
\hline \multicolumn{4}{|c|}{ Average duration of hospital stay } \\
\hline$<1$ days & $72(1.64 \%)$ & $140(5.10 \%)$ & $212(2.98 \%)$ \\
\hline $1-3$ days & $1521(34.83 \%)$ & $896(36.70 \%)$ & $2417(34 \%)$ \\
\hline 4-7 days & $1382(31.66 \%)$ & $804(29.32 \%)$ & $2186(30.75 \%)$ \\
\hline$>7$ days & $1391(31.85 \%)$ & $902(32.89 \%)$ & $2293(32.24 \%)$ \\
\hline \multicolumn{4}{|c|}{ Outcome } \\
\hline Discharged & $3953(90.68 \%)$ & $2353(85.81 \%)$ & $6306(88.72 \%)$ \\
\hline Death & $413(9.35 \%)$ & $389(14.18 \%)$ & $802(11.28 \%)$ \\
\hline \multicolumn{4}{|c|}{ Morbidity profile } \\
\hline Respiratory distress syndrome (RDS) & $352(8.06 \%)$ & $207(7.54 \%)$ & $559(7.86 \%)$ \\
\hline Meconium aspiration syndrome (MAS) & $186(4.26 \%)$ & $125(4.55 \%)$ & $311(4.37 \%)$ \\
\hline Transient tachypnea of newborn (TTNB) & $315(7.21 \%)$ & $84(3.06 \%)$ & $399(5.61 \%)$ \\
\hline Other causes of respiratory distress & $82(1.87 \%)$ & $27(0.98 \%)$ & $109(1.53 \%)$ \\
\hline Birth asphyxia/ HIE & $272(6.22 \%)$ & $256(9.33 \%)$ & $528(7.42 \%)$ \\
\hline Major congenital malformations & $197(4.51 \%)$ & $322(11.74 \%)$ & $519(7.30 \%)$ \\
\hline Sepsis & $801(18.34 \%)$ & $569(20.75 \%)$ & $1370(19.27 \%)$ \\
\hline Pneumonia & $6(0.13 \%)$ & $14(0.51 \%)$ & $20(0.28 \%)$ \\
\hline Meningitis & $1(0.02 \%)$ & $7(0.25 \%)$ & $8(0.11 \%)$ \\
\hline Jaundice requiring phototherapy & $1216(27.85 \%)$ & $346(12.57 \%)$ & $1562(21.97 \%)$ \\
\hline Hypoglycemia & $5(0.11 \%)$ & $5(0.18 \%)$ & $10(0.14 \%)$ \\
\hline Others & $933(21.36 \%)$ & $780(28.44 \%)$ & $1713(24.09 \%)$ \\
\hline
\end{tabular}


Table-2: Mortality profile.

\begin{tabular}{|c|c|c|c|}
\hline \multicolumn{4}{|c|}{ Diseases } \\
\hline & $\operatorname{Inborn}(n=413)$ & Outborn $(n=389)$ & Total $(n=802)$ \\
\hline RDS & $102(24.69 \%)$ & $58(14.91 \%)$ & $160(19.95 \%)$ \\
\hline MAS & $14(3.38 \%)$ & $11(2.82 \%)$ & $25(3.11 \%)$ \\
\hline Birth asphyxia/HIE & $82(19.85 \%)$ & $70(1799 \%)$ & $152(18.95 \%)$ \\
\hline Sepsis & $103(24.93 \%)$ & $97(24.93 \%)$ & $200(24.93 \%)$ \\
\hline Major congenital malformation & $41(9.92 \%)$ & $89(2.87 \%)$ & $130(16.20 \%)$ \\
\hline Prematurity & $45(10.89 \%)$ & $32(8.22 \%)$ & $77(9.60 \%)$ \\
\hline Others & $26(6.29 \%)$ & $32(8.22 \%)$ & $58(7.23 \%)$ \\
\hline \multicolumn{4}{|c|}{ Age at death } \\
\hline$<1$ days & $28(6.77 \%)$ & $41(10.53 \%)$ & $69(8.60 \%)$ \\
\hline 1-3 days & $176(42.6 \%)$ & $162(41.64 \%)$ & $338(42.14 \%))$ \\
\hline 4-7 days & $104(25.18 \%)$ & $82(21.07 \%)$ & $186(23.19 \%)$ \\
\hline$>7$ days & $105(25.42 \%)$ & $104(26.73 \%)$ & $209(26.05 \%)$ \\
\hline \multicolumn{4}{|c|}{ Birth weight } \\
\hline$>2.5 \mathrm{~kg}$ & $84(20.33 \%)$ & $143(37.01 \%)$ & $227(28.30 \%)$ \\
\hline $1.5-2.499 \mathrm{~kg}$ & $169(40.92 \%)$ & $136(34.96 \%)$ & $305(38.02 \%)$ \\
\hline $1-1.499$ & $112(27.11 \%)$ & $75(19.28 \%)$ & $187(23.31 \%)$ \\
\hline$<1 \mathrm{~kg}$ & $48(11.62 \%)$ & $35(8.99 \%)$ & $83(10.34 \%)$ \\
\hline \multicolumn{4}{|c|}{ Gestational age } \\
\hline Preterm & $317(76.75 \%)$ & $204(52.44 \%)$ & $521(64.96 \%)$ \\
\hline Term & $95(23 \%)$ & $180(46.27 \%)$ & $275(34.28 \%)$ \\
\hline Post term & $1(0.24 \%)$ & $5(1.28 \%)$ & $6(0.74 \%)$ \\
\hline
\end{tabular}

Analyzing the morbidity pattern, Jaundice requiring phototherapy (27.85\%) was the leading cause requiring admission in the intramural group followed by sepsis (18.34\%) and respiratory distress $(8.06 \%)$. Among extra mural admissions, sepsis $(20.75 \%)$ is the leading cause followed by jaundice requiring phototherapy (12.57\%), major congenital malformation (11.74\%) and birth asphyxia (9.33\%). Considering both the groups together, jaundice requiring phototherapy $(21.97 \%)$ was the commonest morbidity followed by sepsis (19.27\%) and respiratory distress (7.86\%). All other causes were almost equal in incidence in both groups.

The mortality pattern in the study group is shown in table: 2 . In the study group, $88.72 \%$ were discharged and $11.28 \%$ died. Intramural deaths were $9.45 \%$ and $14.18 \%$ were extra mural deaths. Analyzing the mortality pattern, sepsis was the leading cause of death both among intramural (24.93\%) and extramural (24.93\%). Second common was respiratory distress (19.95\%) which was closely followed by birth asphyxia (18.95\%).

Early neonatal deaths were $73.95 \%$ and $26.05 \%$ deaths occurred after 7 days. Term deaths constituted around one third $(34.28 \%)$ and two third of the deaths $(64.96 \%)$ were preterm. Neonatal deaths among low birth weight babies were $71.7 \%$.

\section{Discussion}

In our study we observed a high percentage of LBW admissions- $49.31 \%$ in Intramural and $48.19 \%$ in Extramural. Sick neonates are referred to our NICU from nearby districts and as the low birth weight babies are prone to serious complications, this could be the reason for having a high incidence of low birth weight neonates in this study. In other studies, it varied between $20 \%$ and $55 \%$. India accounts for $40 \%$ of the world's LBW babies [11-13]. These babies need immediate neonatal care to prevent death and hence focus should be on prevention of LBW babies [14]. The male preponderance in this study is similar to other studies [15-17]. This may be because of vulnerability of male neonates and gender preference. 
In the present study, sepsis and jaundice requiring phototherapy were the leading morbidities observed. Other studies from other places in India presented sepsis and prematurity as the leading cause for admissions [18]. The National Neonatal Perinatal Database shows sepsis (36\%) as the most common morbidity responsible for admission followed by prematurity (26.5\%) and perinatal asphyxia (10\%) [19].

Neonatal sepsis was the cause of morbidity in $19.27 \%$ of admitted neonates. Different hospital-based studies have found the incidence of neonatal sepsis ranging from $17.7 \%$ to $70 \%[11,12,14]$.

In the present study, we observed an incidence of $7.42 \%$ birth asphyxia admissions. Various other studies reported incidence ranging from $12.7 \%$ to $38.7 \%$ $[20,21]$. The incidence of hyper bilirubinemia is $21.97 \%$ in our study. This higher incidence is due to the fact that this study was conducted in a tertiary care referral unit. A similar high incidence of $35 \%$ was also observed in a study by Simiyu [22].

In this study we observed $11.28 \%$ mortality. The mortality in various other studies range from $1.4 \%$ to $20.5 \%[23,24,25]$. The mortality rates depend on many factors like obstetric care, location of referral center, pattern of referral cases, availability of equipments and skilled manpower.

About three fourth of deaths were early neonatal deaths. About $8.6 \%$ of deaths were observed within 24 hours of life and $26.05 \%$ deaths occurred after 7 days of life. There was no difference between mortality rates among intramural and extramural admissions. In a study by Malik S, the incidence of early neonatal death was $82.16 \%$ [26].

\section{Conclusion}

In our study sepsis, hyper bilirubinemia and respiratory distress syndrome were the leading causes of morbidity. Neonatal sepsis can be prevented by enforcing strict hand hygiene and aseptic protocols. Low birth weight and prematurity were the significant contributors to mortality. Hence antenatal programs to prevent prematurity and low birth weight babies should be strengthened. The higher incidence of birth asphyxia and the mortality associated with it in the extramural admissions in the present study warrants strategies to be implemented to prevent birth asphyxia in the referring centers.

\section{What is already known?}

Prematurity, Low birth weight, Sepsis and birth asphyxia were the common causes of neonatal morbidity and mortality.

\section{What this study adds}

Neonatal hyperbilirubinemia is also an important indication for admission in NICU.
In this study the deaths among term babies admitted extramurally were more than the intramurally admitted babies. But the reverse was observed among preterm babies. Other studies observed significantly increased death rates among extramurally admitted babies in both term and preterm groups $[8,26]$. This may be due to the fact that this NICU is a tertiary care referral centre to which other hospitals refer sick neonates at a late stage of the disease. In this study there was no difference in the death rates among intramural and extramural groups due to sepsis.

But in other studies the proportion of deaths due to sepsis in the out born babies was more than inborn babies $[8,26]$. In this study death rate due to birth asphyxia was also similar in both intramural and extramural groups. In other studies a higher death rate due to birth asphyxia was observed in extramural group $[8,26]$. The maternity wing of this hospital is a tertiary care referral centre to which many high risk mothers are referred and hence the incidence of birth asphyxia is more in intramurally admitted neonates.

The mortality among Extreme Low Birth Weight babies in this study is $54.24 \%$. In a study by Modi et al, the mortality among ELBW babies was 62.96\% [27].

Congenitalmalformations were seen in $7.3 \%$ in our study. Similar incidence was observed in other studies [28-30]. Indeveloped countries most of neonatal deaths were attributed to birth defect and extreme prematurity, ow birth weight neonates, while in developingcountries $85 \%$ of neonatal death occur due toperinatal asphyxia, prematurity, low birthweight and sepsis. Studies have showed low cost interventionsand strategies with essential newborn care and training canreduce these major causes of death by more than $50 \%$ [31].

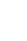


Editorial

Limitations of this study: As this is a retrospective study, cause of death was determined by the information in the official case records. As this was a government hospital-based study and as most of our patients hail from a low socioeconomic status, the results of our study may not be reflecting the actual burden of the disease in the community. Maternal case details were not studied in this study.

Contributors: AV prepared the protocol, enrolled patients, collected and analyzed the data and draftedthe manuscript; KKS: conceptualized and designed the study, supervised data collection and analysis,and critically revised the manuscript. KP and SD: supervised data collection and analysisand critically revised the manuscript.

Funding: Nil, Conflict of interest: None initiated,

\section{Perission from IRB: Yes}

\section{References}

1. Sankar MJ, Neogi SB, Sharma J, Chauhan M, Srivastava R, Prabhakar PK, Khera A, Kumar R, Zodpey S, Paul VK. State of newborn health in India. J Perinatol. 2016 Dec; 36(s3): S3-S8. doi: 10.1038/jp. 2016.183

2. Gonzalez RM, Gilleskie D. Infant Mortality Rate as a Measure of a Country's Health: A Robust Method to Improve Reliability and Comparability. Demography. 2017 Apr; 54 (2):701-720. doi: 10.1007/s13524-0170553-7.

3. Registrar general and census commissioner, India. SRS sample registration system bulletin volume 51 No1, 2017.

4. Bryce J, Boschi-Pinto C, Shibuya K, Black RE; WHO Child Health Epidemiology Reference Group. WHO estimates of the causes of death in children. Lancet. 2005 Mar 26-Apr 1; 365 (9465): 1147-52.

5. Grady SC, Frate SN et al. Neonatal mortality in East Africa, And west Africa-a geographic analysis of district level demographic and heath survey. Geospat Health, 2017 May 26; 12 (1): 501. doi: 10.4081/gh. 2017.501.

6. Lawn JE, Cousens S, Zupan J. Lancet Neonatal Survival Steering Team. 4 million neonatal deaths: when? Where? Why? Lancet 2005; 365: 891-900. DOI: https: //doi.org/ 10. 1016/ S0140-6736 (05)71 048-5.

7. Million Death Study Collaborators, Bassani DG, Kumar R, Awasthi S, Morris SK, Paul VK, Shet A, Ram U, Gaffey MF, Black RE, Jha P. Causes of neonatal and child mortality in India: a nationally representative mortality survey. Lancet. 2010 Nov 27;376(9755):1853-60. doi: 10.1016/S0140-6736 (10) 61461-4. Epub 2010 Nov 12.
8. Kumaravel KS, Ganesh J, Balaji J, Pugalendhiraja $\mathrm{KV}$, Ramesh Babu B. A study on impact of NRHM on Neonatal care and clinical profile Neonates admitted in a SNCU of a rural medical college. Journal of evolution of medical and dental sciences.2015; 82(13); 14335.

9. Kalter HD, HossainM, BurnhamG, Khan NZ, Saha SK et al. Validation of caregiver interviews to diagnose common causes of severe neonatal illness. Indian perinate epidemiol1999;13; 99-113.

10. BangdiwalaSI, NiswadiA, UghadeS, Zodpey S, Integrating results from formative phase studies for informing the design of intervention studies on neonatal health in India. world health popul; 2006 1:1-10.

11. Okechukwu AA, Achonwa A. Morbidity and mortality patterns of admissions into the Special Care Baby Unit of University of AbujaTeaching Hospital, Gwagwalada, Nigeria. Niger J ClinPract. 2009 Dec;12 (4): 389-94.

12. Mukhtar-Yola M, Iliyasu Z. A review of neonatal morbidity and mortality in Aminu Kano Teaching Hospital, Northern Nigeria. Trop Doct 2007; 37:130-2.

13. Shreshtha S, Sharma A, Upadhyay S, Rijal P. Perinatal mortality audit. Nepal Med Coll J 2010;87: 130-8.

14. Oestergaard MZ, Inoue M, Yoshida S, Mahanani WR, Gore FM, Cousens S, et al. Neonatal mortality levels for 193 countries in 2009 with trends since 1990: A systematic analysis of Progress, projections, and priorities. PLoS Med 2011; 8:e1001080.

15. Shakya A, Shrestha D, Shakya H, Shah SC, Dhakal AK. Clinical profile and outcome of neonates admitted to the Neonatal Care Unit at a teaching hospital in Lalitpur, Nepal. Journal of Kathmandu Medical College 2014; 3(4) Issue 10:144-148. 
Editorial

16. Shrestha SP, Shah AK, Prajapati R, YR Sharma YR. Profile of Neonatal Admission At Chitwan Medical College. Journal of Chitwan Medical College 2013; 3 (6): 13-16.

17. Jan AZ, Ahmad S, Zahid SB. Clinical Audit of admission pattern and its outcome in a neonatal ICU.Gomal J Med Sci 2013;11:31-6.

18. Gauchan E, Basnet S, Koirala DP, Rao KS. Clinical profile and outcome of babies admitted to Neonatal Intensive Care Unit (NICU). J Inst Med 2011; 33:1-5.

19. Morbidity and mortality among outbornneonatesat 10tertiary careinstitutions in India during the year2000.J Trop Pediatr. 2004 Jun;50(3):170-4.

20. Mallick AK, Sarkar UK. One year experience of neonatal mortality and morbidity in a state level neonatal intensive care unit and its comparison with national neonatal-perinatal database. J Indian Med Assoc 2010; 108:738-9, 742.

21. Islam MN, Siddika M, Hossain MA, Bhuiyan MK, Ali MA. Morbidity pattern and mortality of neonates admitted in a tertiary level teaching hospital in Bangladesh.Mymensingh MedJ.2010 Apr;19(2):159-62.

22. Simiyu DE. Morbidity and mortality of neonates admitted in general paediatric wards at Kenyatta National Hospital. East Afr Med J. 2003 Dec;80(12): 611-6.

23. Patil Ravindra B, KoppadRaghavendraswamy, BenakanalShreeshail.Clinical Profile and Outcome of Babies Admitted to Neonatal Intensive Care Unit (NICU), Mc Gann Teaching Hospital Shivamogga, Karnataka: A Longitudinal Study. Sch. J. App. Med. Sci., 2014; 2 (6G): 3357-3360.

24. Sridhar PV, Thammanna PS, Sandeep M. Morbidity Pattern and Hospital Outcome of Neonates Admitted in a Tertiary Care Teaching Hospital, Mandya. Intl J Sci Study 2015;3(6): 126-129.

25. Rakholia R, Rawat V, Bano M, Singh G. Neonatal morbidity and mortality of sick newborns admitted in a teaching hospital of Uttarakhand. CHRISMED J Health Res 2014; 1:228-34.

26. Malik S, Gohiya P, Khan IA. Morbidity profile and mortality of neonates admitted in Neonatal Intensive Care Unit of a Central India Teaching Institute: A prospective observational study. J ClinNeonatol 2016; 5: 168-73.

27. Modi R, Modi B, Patel JK, Punitha KM. Study of the Morbidity and the Mortality Pattern in the Neonatal Intensive Care Unit at a TertiaryCare teaching Hospital in Gandhinagar District, Gujarat, India. J Res Med Den Sci 2015;3(3):208-12.

28. Taksande A, Vilhekar K, Chaturvedi P, Jain M. Congenital malformations at birth in Central India: A rural medical college hospital based data. Indian J Hum Genet 2010; 16:159-63.

29. National Neonatal Perinatal Database. Report for Year 2000. National NeonataologyFoum India; 2000.

30. Neonatal - Perinatal database and birth defects surveillance. Report of regional review meeting. New Delhi, India: World Health House SEARO;2014. p. 3-6.

31. Carlo WA, Goudar SS, Jehan I, Chomba E, Tshefu A, Garces A, Parida S, Althabe F, McClure EM, Derman RJ, Goldenberg RL, Bose C, Krebs NF, Panigrahi P, Buekens P, Chakraborty H, Hartwell TD, Wright LL; First Breath Study Group. Newborn-care training and perinatal mortality in developing countries. N Engl J Med. 2010 Feb 18;362(7):614-23. doi: 10. 1056 /NEJMsa0806033.

\section{How to cite this article?}

Anurekha V, Kumaravel KS, Kumar P, Satheesh kumar D. Clinical profile of neonates admitted to a neonatal intensive care unit at a referral hospital in South India. Int J Pediatr Res. 2018;5(2):72-77. doi:10.17511/ijpr.2018.i02.06. 